\title{
History and Development of Accessories for Endoscopic Submucosal Dissection
}

\author{
Bong Min Ko \\ Digestive Disease Center and Research Institute, Department of Internal Medicine, Soonchunhyang University Hospital , Bucheon, Korea
}

Endoscopic submucosal dissection (ESD) procedure is composed of circumferential mucosal incision and submucosal dissection. A variety of endoscopic accessories are required to perform mucosal incision and submucosal dissection safely. As a result of the improvements in ESD devices and peripheral equipment and development of the ESD technique, ESD procedures have been performed extensively worldwide. Here I review the history of the development of accessories used in performing ESD procedures. Clin Endosc 2017;50:219-223

Key Words: Dissection, Endoscopic submucosal; Endoscopic mucosal resection; Endoscopic accessory; Mucosal incision

\section{INTRODUCTION}

Endoscopic submucosal dissection (ESD) is a procedure conducted for removing lesions en bloc, regardless of the location, shape, and size of tumors and presence of combined ulcer in the gastrointestinal (GI) tract. The ESD technique is mainly used for the removal of gastric lesions; however, it has also been recently applied to remove lesions in the esophagus and colorectum. As a result of the improvements in ESD devices and peripheral equipment and the development of the ESD technique, the use of GI ESD has spread extensively worldwide. The technology of ESD is evolving gradually and has made endoscopic resection safer, easier, and more reliable. This report focuses on the history of the development of accessories used in performing ESD procedures for GI lesions using published studies.

Received: May 22, 2017 Revised: May 23, 2017

Accepted: May 23, 2017

Correspondence: Bong Min Ko

Digestive Disease Center and Research Institute, Department of Internal Medicine, Soonchunhyang University Hospital, 170 jomaru-ro, Wonmi-gu, Bucheon 14584 , Korea

Tel: +82-32-621-5096, Fax: +82-32-621-5080, E-mail: kopa9445@schmc.ac.kr

(c) This is an Open Access article distributed under the terms of the Creative Commons Attribution Non-Commercial License (http://creativecommons.org/ licenses/by-nc/3.0) which permits unrestricted non-commercial use, distribution, and reproduction in any medium, provided the original work is properly cited.

\section{KNIVES}

The knife used in the ESD technique varies widely worldwide. The devices for ESD are divided into two general categories: needle-knife type and scissors type. ${ }^{1}$ Further, ESD knives can be classified into two types, according to the safety tool applied: a blunt tip and a tip-cutting knife. ${ }^{2}$ Blunt tip ESD knives include Insulated-tip knife (IT knife, Olympus, Tokyo, Japan), Safe Knife V (Fujifilm, Tokyo, Japan), Mucosectom (Pentax, Tokyo, Japan), and Swan blade (Pentax, Tokyo, Japan) (Fig. 1). Tip-cutting ESD knives include hook knife (Olympus Medical System, Tokyo, Japan), flex knife (Olympus Medical System, Tokyo, Japan), dual knife (Olympus Medical System, Tokyo, Japan), flush knife (Fujifilm, Tokyo, Japan), and Hybrid knife (ERBE, Erlangen, Germany) (Fig. 2). In Korea, several knives are available for ESD, such as the needle knife, IT knife, hook knife, flex knife, and dual knife. Each of them has some advantage and disadvantage, and their methods of use are different.

\section{Needle knife and IT knife (Olympus, Tokyo, Japan)}

The needle knife was used for endoscopic resection with local injection of hypertonic saline-epinephrine solution (ERHSE), For the mucosal layer incision after saline injection, the use of a simple diathermy needle knife has a high risk for perforation and bleeding. Therefore, safer ESD procedures 

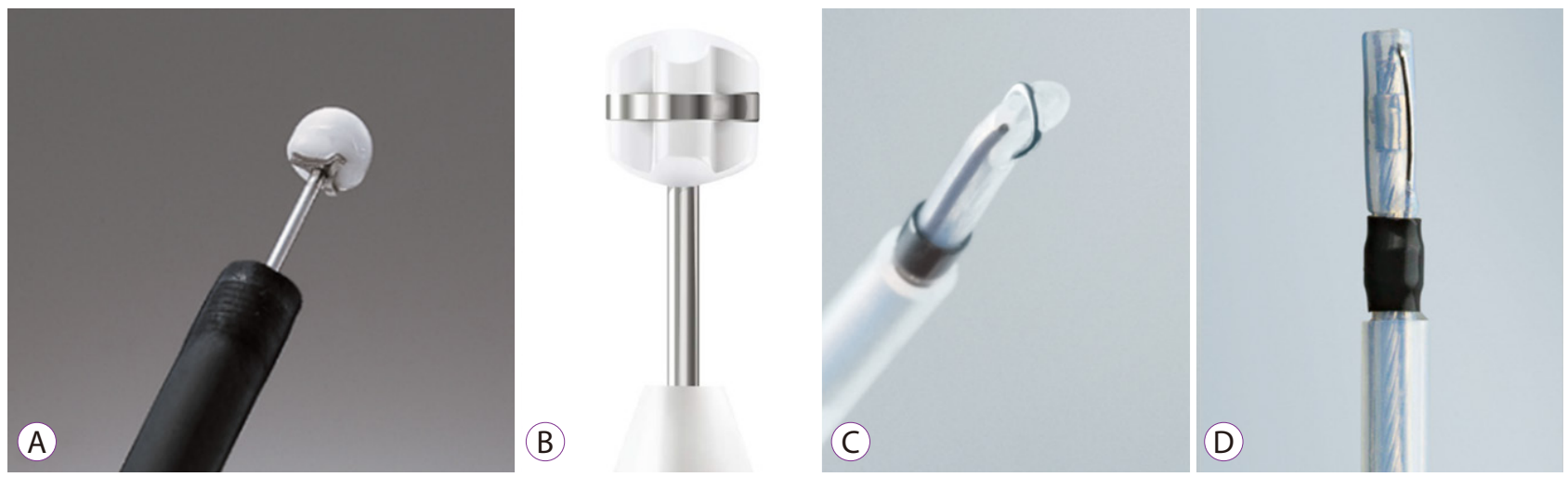

Fig. 1. Blunt tip endoscopic submucosal dissection (ESD) knives. (A) IT knife (Olympus, Tokyo, Japan). (B) Safe Knife V (Fujifim, Tokyo, Japan). (C) Mucosectom (Pentax, Tokyo, Japan). (D) Swan blade (Pentax, Tokyo, Japan).
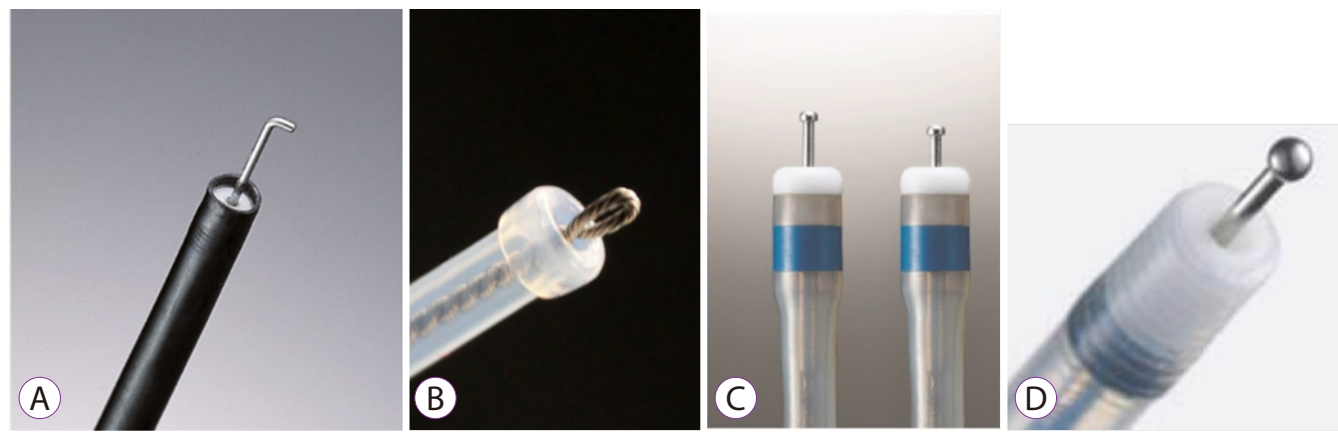

(E)

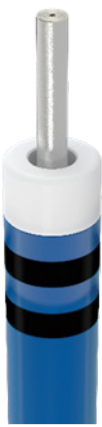

Fig. 2. Tip-cutting endoscopic submucosal dissection (ESD) knives. (A) Hook knife (Olympus, Tokyo, Japan). (B) Flex knife (Olympus, Tokyo, Japan). (C) Dual knife (Olympus, Tokyo, Japan). (D) Flush knife BT (Fujifim, Tokyo, Japan). (E) Hybrid knife (ERBE, Erlangen, Germany).
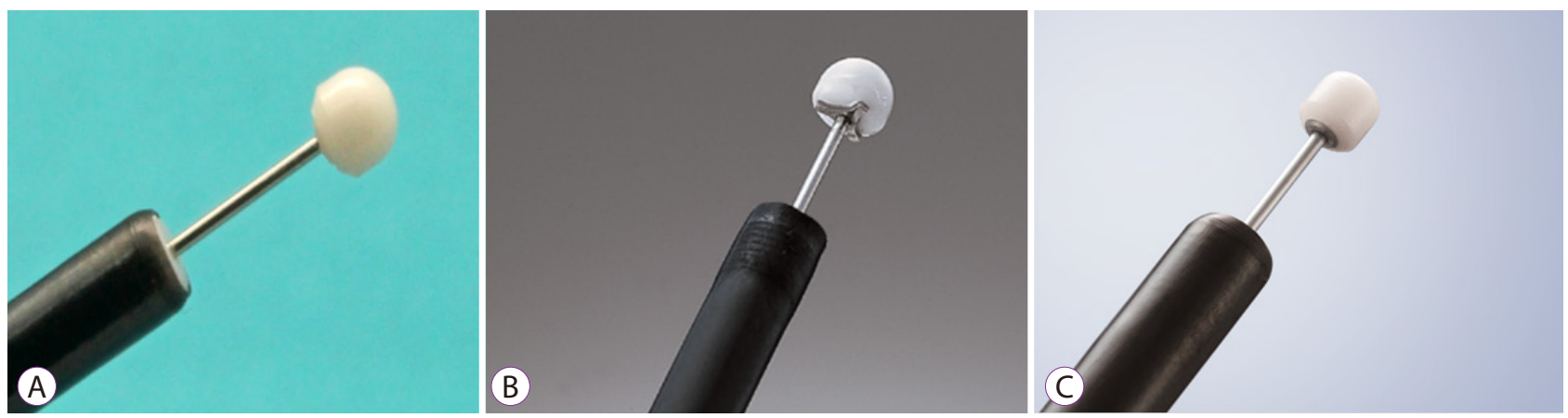

Fig. 3. IT knife series (Olympus, Tokyo, Japan). (A) Original IT knife. (B) IT knife 2. (C) IT knife nano.

needed improved instruments. The IT knife was designed to solve problems found during the endoscoic mucosal resection (EMR) and ERHSE techniques for the removal of early gastric cancer tumors at the National Cancer Center Hospital established in the late 1990s.

In 1995, Hosokawa and Yoshida developed and used a new EMR technique using an IT knife (Fig. 3) to remove a large lesion in a single piece completely and obtained good results. ${ }^{3}$ The IT knife is still being used for gastric ESD procedures.

The IT knife 2 (Fig. 3) is an improved version of the IT knife, which Ono et al. developed and published in $2008{ }^{4}$ The electrosurgical Olympus IT knife $2^{\text {mi }}$ features a special electrode on the proximal side of the isolated ceramic tip designed to help minimize cutting invasiveness while maximizing cutting abilities in both vertical and horizontal directions.

\section{Flex knife (Olympus, Tokyo, Japan)}

There was a clinical announcement on flex knives in 2003. ${ }^{5}$ The use of the flex knife has been reported to supplement the limitations of the IT knife in early gastric cancer. ${ }^{6}$ The electrosurgical Olympus Flex Knife ${ }^{\text {tix }}$ features an adjustable loop designed to deliver cutting flexibility and enable easy incision 
and dissection in all directions during an ESD procedure.

\section{Hook knife (Olympus, Tokyo, Japan)}

In 2005, Oyama et al. reported a case of esophageal cancer used a hook knife. ${ }^{7}$ The electrosurgical Hook Knife ${ }^{\mathrm{mi}}$ features a rotatable, L-shaped hook that allows cutting in horizontal and vertical directions. It can be used for both incisions and dissections and is ideal for cutting fibrous tissues.

\section{Dual knife (Olympus, Tokyo, Japan)}

Recently, the dual knife was further developed. With the addition of a convenient jet, the new and evolved Dual knife $J^{\text {st }}$ (Fig. 4) can help endoscopists work and reduce the time it takes to perform ESD procedures.

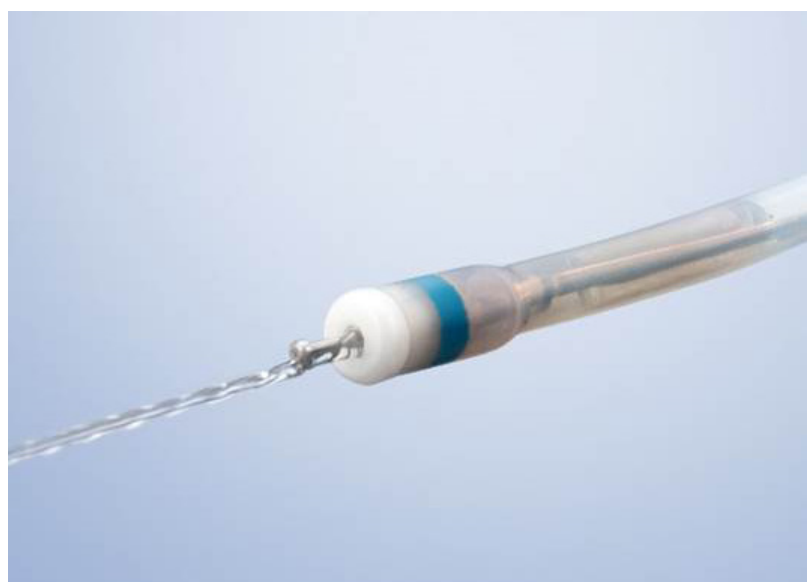

Fig. 4. Dual knife JTM (Olympus, Tokyo, Japan).

\section{Stage beetle (SB) knife (Sumitomo Bakelite, Tokyo, Japan)}

In 2010, Honma et al. developed a scissors-type grasping device called an "SB knife" which is mainly used for gastric ESD procedures. The SB knife Jr (Sumitomo Bakelite, Tokyo, Japan) (Fig. 5) can be used for colorectal ESD procedures; these knives are particularly useful for submucosal dissection of lesions. The SB knife has a curved tip that allows to keep the proper dissecting layer and prevents unexpected muscular layer injuries. However, this knife is not widely used in Korea.

\section{Hybrid knife (ERBE, Erlangen, Germany)}

An ESD procedure using the hybrid knife was reported in

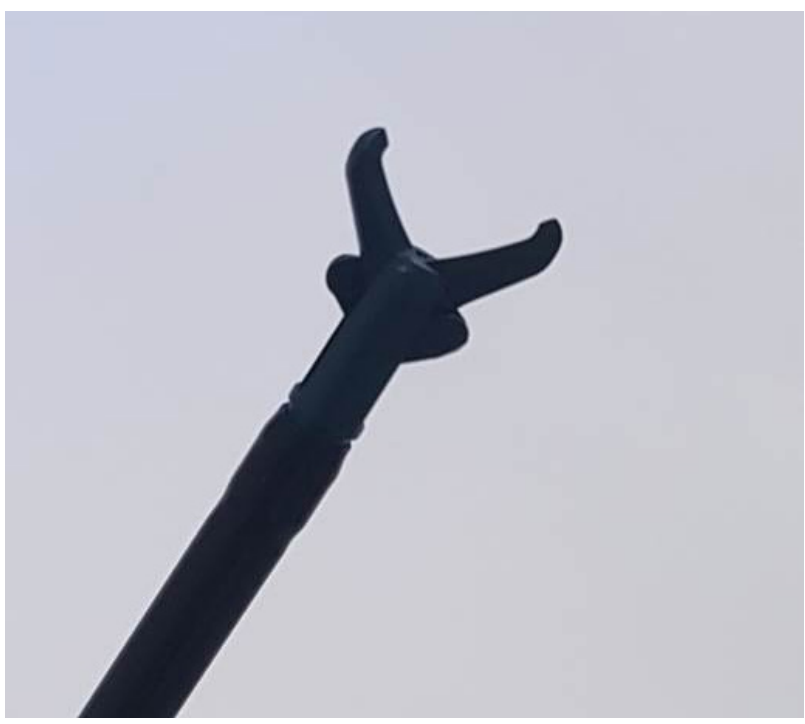

Fig. 5. Stage beetle knife Jr (Sumitomo Bakelite Co., Tokyo, Japan).

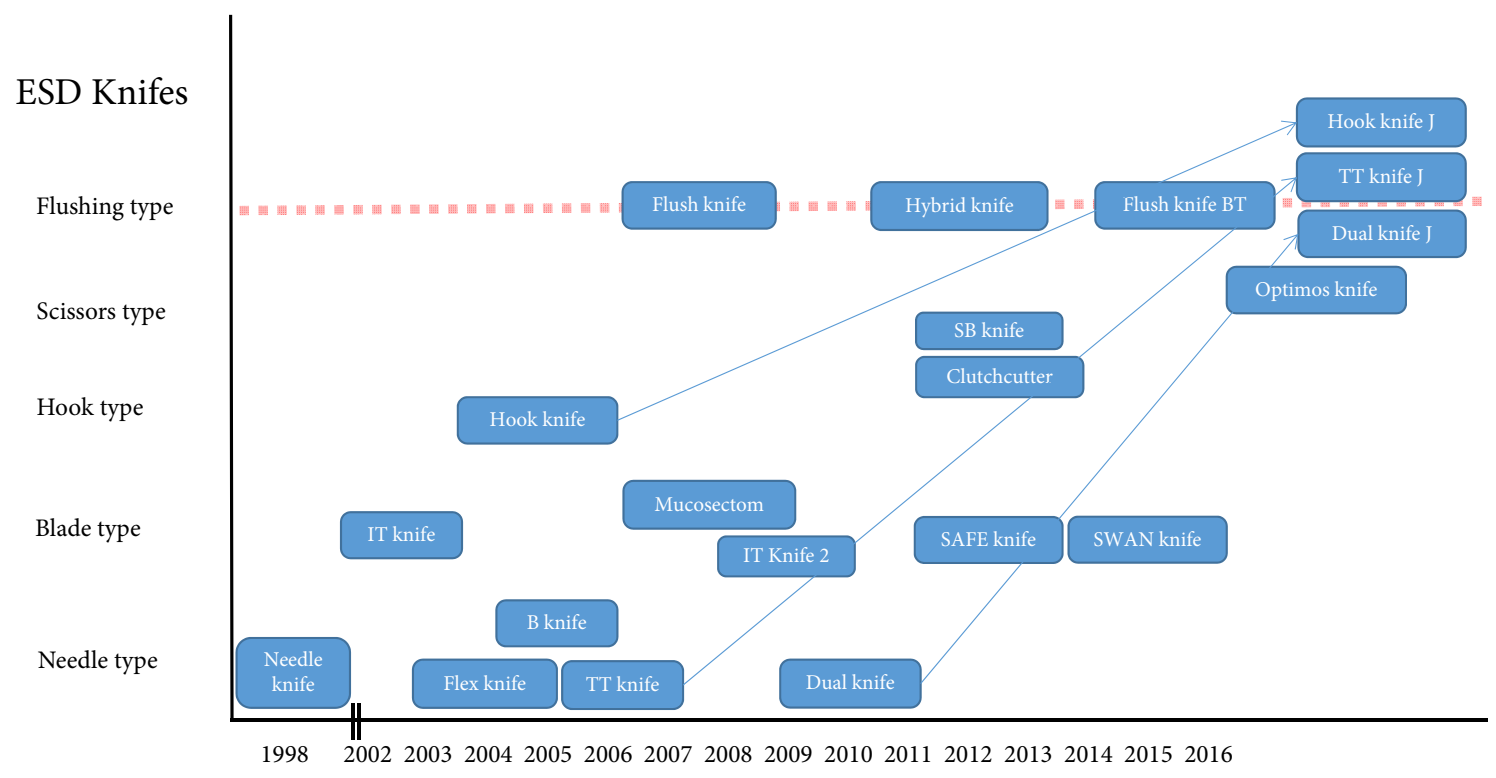

Fig. 6. Each knife for gastrointestinal (GI) endoscopic submucosal dissection (ESD) and its release year. Adapted from Tanaka et al. ${ }^{11}$ 

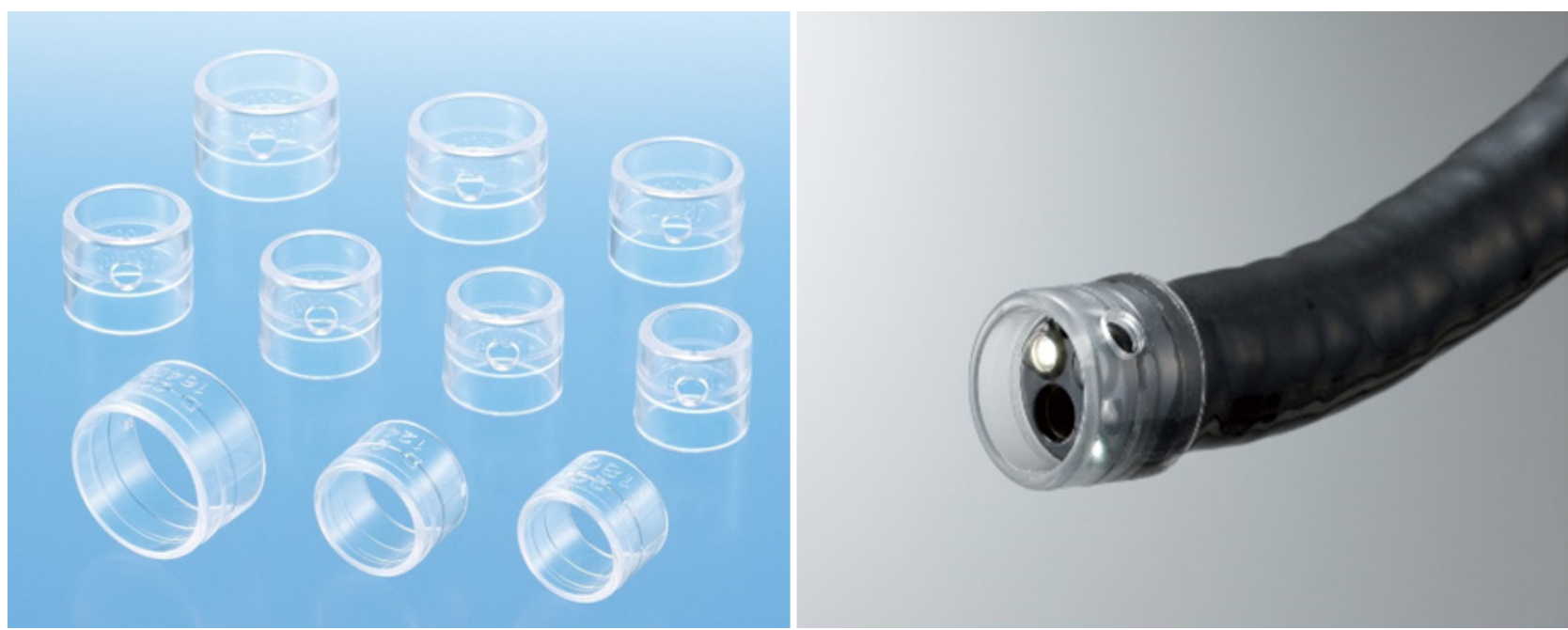

Fig. 7. Distal attachment (Olympus Medical System, Tokyo, Japan).
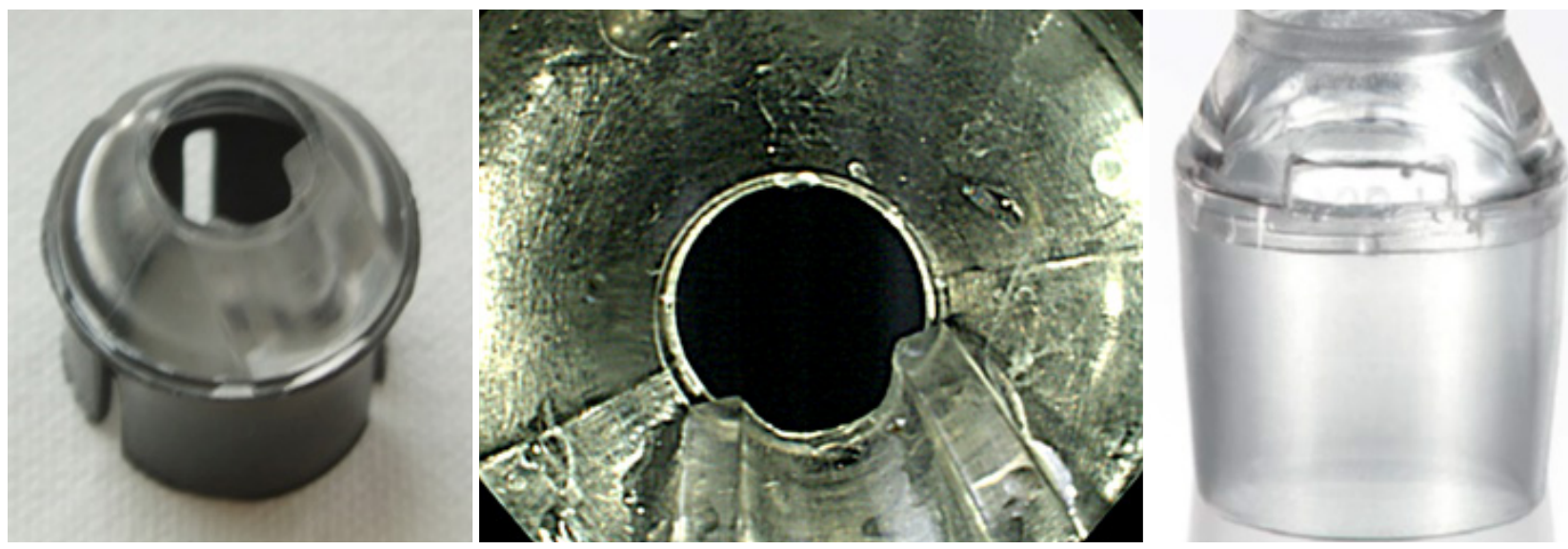

Fig. 8. Development of the ST hood (Fujifilm, Tokyo, Japan).

a porcine model in $2009 .^{9}$ This technology allows needleless submucosal infusion and lifting, as well as mucosal incision and coagulation for ESD of mucosal areas without changing the tool. The use of the water jet dissector in combination with the hybrid knife seems to accelerate the ESD procedure and may increase its safety and efficacy according to experimental studies.

\section{Current directions for knife development}

Recently, in terms of quality controlled ESD, ${ }^{10}$ new types of knives or redeveloping knives are trendy and available to perform a submucosal injection during a submucosal dissection (Fig. 6). ${ }^{11}$

\section{DISTAL ATTACHMENT}

Endoscopic attachments aid in visualization by maintaining distance from the lesion tissue and provide countertraction that is necessary to enter the submucosal area. Endoscopic distal attachments are either straight (Fig. 7), oblique, or tapered (Fig. 8).

The small-caliber tip transparent hood was unveiled in 2003 by Yamamoto and has undergone changes since then. ${ }^{12}$ Currently, there has been a great deal of development by the Fujifilm Corporation.

\section{COAGULATION DEVICE}

Recently, bleeding vessels are coagulated using coagulation forceps, such as hot biopsy forceps (Olympus, Tokyo, Japan), monopolar Coagraspers (Olympus, Tokyo, Japan), and bipolar HemoStat-Y (Pentax, Tokyo, Japan). 


\section{SUBMUCOSAL INJECTION SOLUTIONS}

A submucosal injection fluid is a safety material that avoids deep muscle damages during endoscopic resections. Classical injections are usually sufficient for conventional endoscopic resection; however, it needs more durable and reliable submucosal injection solutions during time-consuming ESD procedures. The efficacy of various viscous and highly osmotic solutions in producing a long-lasting submucosal injection material has been studied. Various submucosal injection solutions, such as dextrose, glycerol, hydroxypropyl methylcellulose solutions, and MUCOUP (Johnson \& Johnson, Tokyo, Japan), are used for ESD procedures.

\section{CONCLUSIONS}

The ESD technique and accessories are continuously developing for the removal of GI tumors. The endoscopists performing ESD procedures should receive appropriate training and education according to the changing environment of such procedures.

\section{Conflicts of Interest}

The author has no financial conflicts of interest.

\section{REFERENCES}

1. Gotoda T, Ho KY, Soetikno R, Kaltenbach T, Draganov P. Gastric ESD: current status and future directions of devices and training. Gastrointest Endosc Clin N Am 2014;24:213-233.

2. Sumiyama K, Tajiri H. History of ESD. In: Fukami N, ed. Endoscopic submucosal dissection: principles and practice. New York (NY): Springer-Verlag New York; 2015. p. 3-8.

3. Hosokawa K, Yoshida S. [Recent advances in endoscopic mucosal resection for early gastric cancer]. Gan To Kagaku Ryoho 1998;25:476-483.

4. Ono H, Hasuike N, Inui T, et al. Usefulness of a novel electrosurgical knife, the insulation-tipped diathermic knife-2, for endoscopic submucosal dissection of early gastric cancer. Gastric Cancer 2008;11:47-52.

5. Yahagi N. En-bloc resection of colorectal neoplasma by submucosal dissection method using flex knife. Early Colorectal Cancer 2003;7:550556.

6. Yahagi N, Fujishiro M, Kakushima N, et al. Endoscopic submucosal dissection for early gastric cancer using the tip of an electrosurgical snare (thin type). Dig Endosc 2004;16:34-38.

7. Oyama T, Tomori A, Hotta K, et al. Endoscopic submucosal dissection of early esophageal cancer. Clin Gastroenterol Hepatol 2005;3(7 Suppl 1):S67-S70.

8. Honma K, Kobayashi M, Watanabe $\mathrm{H}$, et al. Endoscopic submucosal dissection for colorectal neoplasia. Dig Endosc 2010;22:307-311.

9. Neuhaus H, Wirths K, Schenk M, Enderle MD, Schumacher B. Randomized controlled study of EMR versus endoscopic submucosal dissection with a water-jet hybrid-knife of esophageal lesions in a porcine model. Gastrointest Endosc 2009;70:112-120.

10. Toyonaga T, Nishino E, Man-I M, East JE, Azuma T. Principles of quality controlled endoscopic submucosal dissection with appropriate dissection level and high quality resected specimen. Clin Endosc 2012;45:362374.

11. Tanaka S, Terasaki M, Kanao H, Oka S, Chayama K. Current status and future perspectives of endoscopic submucosal dissection for colorectal tumors. Dig Endosc 2012;24 Suppl 1:73-79.

12. Yamamoto H, Kawata H, Sunada K, et al. Successful en-bloc resection of large superficial tumors in the stomach and colon using sodium hyaluronate and small-caliber-tip transparent hood. Endoscopy 2003;35:690694. 